\title{
What is Diabetes Remission?
}

Jens J. Holst (1) · Sten Madsbad

Received: February 5, 2021 / Accepted: February 10, 2021 / Published online: February 20, 2021

(C) The Author(s) 2021

Keywords: Bariatric surgery; Hemoglobin A1c; Type 2 diabetes pathophysiology; Weight loss

\section{Key Summary Points}

Remission of type 2 diabetes is generally thought of as being able to maintain hemoglobin A1c (HbAc1) levels below a certain threshold without any antidiabetic therapy.

New dietary regimes resulting in major weight losses have resulted in remission according to this definition and have raised hopes that diabetes can be cured by healthy dieting and that antidiabetic agents are superfluous.

In this commentary we review the background for the current HbA1c thresholds and discuss the possibilities of obtaining true remission of diabetes.

\section{J. J. Holst (更)}

The Department of Biomedical Research, University of Copenhagen, Copenhagen, Denmark

e-mail: jjholst@sund.ku.dk

\section{J. J. Holst}

The NovoNordisk Foundation Center for Basic

Metabolic Research, Copenhagen, Denmark

\section{S. Madsbad}

Department of Endocrinology, Hvidovre Hospital, University of Copenhagen, Copenhagen, Denmark

\section{DIGITAL FEATURES}

This article is published with digital features, including a summary slide, to facilitate understanding of the article. To view digital features for this article, go to https://doi.org/10.6084/ m9.figshare.13747018.

\section{INTRODUCTION}

In the article: "What's in a name? Redefining Type 2 diabetes remission," Sanjay Kalra, Arbinder Singal and Tejal Lathia from Karnal, India, discuss the phenomenon of diabetes remission and review existing definitions of the condition [1]. On this background, they move on to propose that diabetes remission is defined as a healthy clinical state characterized by the achievement of glycated hemoglobin (HbA1c) levels below the targeted level that are maintained for at least 6 months, with or without continued use of lifestyle modification and/or metformin, provided that this is not due to complications, comorbid conditions or concomitant therapy.

The main inspiration for these authors to propose the new definition was apparently the use of the term in the field of oncology, where the precise meaning of the word is of the utmost importance to the patient and his/her family because of the dire prognosis in the 
absence of therapeutic attempts to achieve remission. In the field of diabetes management, the relevance of the concept of "remission" lies in its prognostic value in terms of time to complications and no need of antidiabetic treatment; as such, its meaning differs from that in oncology. Of course, an abbreviated life expectancy is also a threat in patients with type 2 diabetes (T2DM), but the risk of premature mortality in this patient population is much lower when receiving adequate treatment even in the absence of remission. Importantly, the current use of HbA1c levels to define successful treatment has its background in extensive studies on the prognostic value of the cutoff level in terms of the risk of late diabetic complications, in particular retinopathy [2]. Thus, the generally accepted level of $7.0 \%$ for good glycemic control is a compromise, and quite far from a state of remission regardless of how you define it; rather, it defines an "acceptable" treatment result, obtained without unduly increasing the risk of adverse events associated with the therapy itself. The ACCORD study [3] is a dramatic illustration of the struggle to improve HbA1c levels further with intensified medication in order to obtain remission; HbA1c was successfully reduced, but the effort turned out to be associated with increased mortality. Several clinical position statements recommend 7.0 or $6.5 \%$ as "optimal" HbA1c targets $[2,4,5]$. Characteristically, there is no unanimous agreement on the target level, with some Associations preferring $6.5 \%$, some $7.0 \%$, while others recommend different levels for different populations, such as the elderly or people with short life expectancy; this lack of consensus clearly illustrates the differential "political" strategies behind the compromise.

\section{CURRENT DEFINITIONS OF REMISSION}

In 2009, Buse and coworkers subdivided remission into two categories, namely partial and complete [6]. Partial remission is defined as $\mathrm{HbA} 1 \mathrm{c}<6.5 \%(48 \mathrm{mmol} / \mathrm{mol})$ and fasting glucose between 5.6 and $6.9 \mathrm{mmol} / \mathrm{l}$ maintained for at least 1 year in the absence of active pharmacological therapy or ongoing antidiabetic procedures. Complete remission is a return to normal measures of glucose metabolism with HbA1c in the normal range $(<6.0 \%[42 \mathrm{mmol} /$ mol]) and fasting glucose $<5.6 \mathrm{mmol} / \mathrm{l}$. Prolonged remission is defined as remission lasting for $>5$ years. The 2009 definitions are not without problems since the day-to-day variations in plasma glucose are rather wide in a person with T2DM in remission, which in combination with the imprecision of the plasma glucose measurements may result in a shift between partial versus complete remission from day to day [7]. Further, in some countries the definition "impaired fasting glucose" (IFG: fasting plasma glucose [FPG] of between 5.6 and $7.0 \mathrm{mmol} / \mathrm{l}$ ) is not an officially registered diagnosis used in clinical practice. The 2009 definition is also complex in relation to the diagnostic coding systems.

An operative position statement on remission was published by the joint Association of British Clinical Diabetologists (ABCD) and the Primary Care Diabetes Society (PCDS) defining remission as both FPG concentration $<7 \mathrm{mmol} / \mathrm{l}$ and $\mathrm{HbA} 1 \mathrm{c}<48 \mathrm{mmol} / \mathrm{mol}$ on two occasions separated by at least 6 months $[8,9]$. This definition is pragmatic, fits with the diagnostic criteria for diabetes and is easy for patients to understand and for physicians to use.

However, the discussion of the concept of remission of T2DM has reached new timeliness recently, in particular because of two therapeutic successes: the effects of bariatric surgery $[10,11]$ and the results of effective weight loss therapies, as recently illustrated in the DiRECT trial [12]. In both cases, the therapy frequently leads to remission. For example, in the DiRECT trial, remission was obtained in $85 \%$ of those patients with T2DM who obtained a weight loss of $\geq 15 \%$. Similar results are often seen after bariatric surgery, where weight loss may reach $40 \mathrm{~kg}$ at 1-2 years after surgery, with the rate of remission of $70-80 \%$.

The definition of remission applied in the DiRECT study focused on HbA1c $<48 \mathrm{mmol} /$ mol after least 2 months of termination of all antidiabetic medications [6]. The background for this definition is in line with daily clinical 
practice, where HbA1c measurements are recommended in the screening and diagnosing of diabetes as well as in the evaluation of the glycemic status of a diabetic patient. However, it is important to consider that patients with T2DM in remission according to the criteria discussed above characteristically exhibit elevated cardiovascular risk factors, including lipid abnormalities and hypertension, and are considered to at high risk of cardiovascular disease (CVD). Consequenty, despite remission based on the HBA1c target, focus should also remain on the treatment of low-density lipoprotein (LDL). The LDL target should be a LDL level $<2.5 \mathrm{mmol} / 1$ in patients without CVD and $\leq 1.8 \mathrm{mmol} / \mathrm{l}$ in patients with established CVD or with a very high risk for CVD, i.e. albuminuria and labile hypertension. The level for blood pressure should be $<130 / 80 \mathrm{mmHg}$. It is of key importance to check these cardiovascular risk factors at least annually.

The effect of long-term remission on late diabetic microvascular complications is sparsely investigated, but there are reports of regression after pancreas transplantation and bariatric surgery. The regression of even pre-existing diabetic kidney disease has been reported after bariatric surgery. The risk of macrovascular complications was reduced after bariatric surgery with long-term remission of diabetes. Nevertheless, an individual evaluation of the occurrence of late diabetic complications is needed during follow-up. Established complications likewise need continuing assessment.

\section{PATHOPHYSIOLOGY OF REMISSION IN T2DM}

The dieting approach as applied in the DiRECT studies has especially reopened a discussion on the nature of T2DM, in particular among lay people, leading to questioning of the need for pharmacotherapy and praise of lifestyle interventions, based on the concepts that T2DM is the result of the modern lifestyle and therefore modifiable and that medical intervention has no place in its mitigation.

It is necessary to consider the pathogenesis of the disease when discussing remission. Why do we get T2DM? Immediately major problems immediately pop up: the multifactorial pathogenesis of non-insulin-dependent diabetes as well as its many faces (some researchers seem to compete in identifying new subtypes nowadays $[13,14])$. For the current discussion, we should probably leave out secondary diabetes (pancreatic, hepatic, steroid- and growth hormone-induced, etc.) and concentrate on the main types. Supported by the authors' own research and literature studies, the working hypothesis in our group is based mainly on a dual pathogenesis for T2DM: a fundamental factor is a polygenic disposition, which primarily lies in the pancreatic genes associated with beta-cell function $[15,16]$, resulting in an impaired beta-cell function, as further discussed below. However, an individual with this disposition does not necessarily develop the disease until another important factor shows up: overweight/obesity. The obesity leads to insulin resistance in a number of important tissues (in particular the liver and muscles) which impairs insulin action [16]. In addition, hepatic steatosis impairs glucagon's effects on hepatic amino acid metabolism, and rising amino acid levels cause hyperglucagonemia $[17,18]$. These two endocrine disturbances lead to increases in hepatic glucose production, as well as lipid metabolism and peripheral glucose metabolism abnormalities.

Viewed in this way, it is no wonder that a major weight loss can result in diabetes remission. The precipitating factor, the obesity, which originally tilted the boat toward diabetes, has been eliminated. But has the disease disappeared? Of course not, but as long as the individual is able to keep maintain an appropriate body weight and low ectopic fat levels, an apparent remission will be maintained [19]. Unfortunately, this is not usually what happens after life-style interventions, although it is often successfully achieved after bariatric surgery [20]; and, conversely, if the operated patient puts on weight after the operation, the remission disappears again and in many patients the diabetes returns [21]. The question is now whether the initial effect should be designated remission? There is another recent development which is highly relevant to this discussion: while 
traditional pharmacological weight loss therapies may bring about some metabolic benefits, they have generally not been associated with diabetes remission. However, with the most recent developments, particularly those associated with glucagon-like peptide- 1 receptor agonists (GLP-1 RAs), we have arrived at a place where we can expect average weight losses exceeding the $15 \%$ mentioned above; as such, these agents may also lead to a more lasting diabetes remission with $\mathrm{HbA} 1 \mathrm{c}<6.5 \%$ (48 mmol/mol) [22]. Indeed the GLP-1 RAs are already known to greatly reduce the risk of developing T2DM (which is of course high in individuals with obesity) during therapy [23], but the moment therapy is terminated, body weight increases again, and diabetes returns.

After weight loss induced by bariatric surgery or the use of a very low calorie diet of $600-800 \mathrm{kcal} / \mathrm{day}$, the apparent remission shows up very rapidly, even before a major weight loss occurs, due to a reduction in liver fat and hence an improvement in liver insulin sensitivity $[19,24]$. The effect of introducing a very low calorie diet as therapy to persons with early diabetes can be normal FPG values in many persons within a few days. Later, after a major weight loss, skeletal muscle insulin sensitivity will also improve (presumably due to the loss of ectopic fat), and beta-cell function may improve steadily over months $[19,25]$.

Importantly, the clinical fact is that the weight loss required to reverse T2DM is much greater than that conventionally advised, and most studies using lifestyle-based weight loss intervention have only achieved modest reductions in weight (3-4 kg) and HbA1c levels [26]. Subjects with type 1 diabetes very rarely obtain remission based on current definitions.

The natural history of T2DM is characterized by progressive deterioration of pancreatic betacell function leading to progressively increased requirements for glucose-lowering therapy. Thus, in clinical practice, insulin is often introduced after years of diabetes and use of several antidiabetic agents [4]. Beta-cell failure is explained by two factors, a reduction in betacell mass and a loss of function [27, 28]. Glucotoxicity, induced by chronic hyperglycemia, is one of the mechanisms leading to beta-cell failure [28]. Optimum glycaemic control will reduce glucotoxicity and induce improvement in beta-cell function [28]. The improved betacell function also includes enhanced responsiveness to the gut hormones GLP-1 and gastric inhibitory polypeptide (GIP), which are the major regulators of postprandial insulin secretion [28]. However, if impaired beta-cell function is already apparent, weight losses cannot result in remission, although improvements may still occur. Apart from weight loss, studies have indicated that early, typically from the time of diagnosis, intensive insulin treatment with strict glycemic control (from 2 to 14 weeks) titrated to normalize fasting and postprandial glucose levels may also result in long-term beneficial effects on beta-cell function and insulin sensitivity [29-31]. However, strict control implies multiple insulin injections or pumps, an option that is not attractive to persons with early T2DM, and this approach does not result in long-term improvement in more advanced disease.

The results of theDiRECT study, bariatric surgery and use of intensive insulin treatment have disproven the belief that beta-cell function invariably declines progressively with time. Independent of the therapeutic approach used, be it weight loss via changes in lifestyle, bariatric surgery or intensive insulin treatment, the chance for remission of diabetes is greatest when the intervention is introduced early in the disease when the patients still have a beta-cell mass with a functional reserve that can overcome the ambient insulin resistance [32]. In this case, early means the first years after diagnosis, and chances of remission are best in subjects treated with only one or two antidiabetic agents. Most patients treated with several antidiabetic agents, including insuli, $\mathrm{n}$ will not obtain remission, even after major weight loss obtained after bariatric surgery, because of irreversible beta-cell damage [33].

On this background, we recommend not talking too much about remission to patients, who after successful dieting or surgery may think that they are cured of the disease, if the remission criteria, as suggested by Kalra et al. [1] or others, are fulfilled. But they are not: the minute they let their weight and lifestyle 
control go, the disease will return. Rather than talking about remission, we should focus on the importance of maintaining a healthy lifestyle, perhaps with some help from effective pharmaceuticals to combat obesity and maintain appropriate glucose levels, for which the patients will be rewarded with significantly improved prognosis with respect to both the debilitating complications and mortality.

\section{ACKNOWLEDGEMENTS}

Funding. No funding or sponsorship was received for this study or publication of this article.

Authorship. All named authors meet the International Committee of Medical Journal Editors (ICMJE) criteria for authorship for this article, take responsibility for the integrity of the work as a whole, and have given their approval for this version to be published.

Disclosures. Jens J. Holst and Sten Madsbad declare that they have nothing to disclose.

Compliance with Ethics Guidelines. This article is based on previously conducted studies and does not contain any new studies with human participants or animals by any of the authors.

Peer Review. Please note, contrary to the journal's standard single-blind peer review process, as a commentary this article underwent review by a member of the journal's Editorial Board.

Open Access. This article is licensed under a Creative Commons Attribution-NonCommercial 4.0 International License, which permits any non-commercial use, sharing, adaptation, distribution and reproduction in any medium or format, as long as you give appropriate credit to the original author(s) and the source, provide a link to the Creative Commons licence, and indicate if changes were made. The images or other third party material in this article are included in the article's Creative Commons licence, unless indicated otherwise in a credit line to the material. If material is not included in the article's Creative Commons licence and your intended use is not permitted by statutory regulation or exceeds the permitted use, you will need to obtain permission directly from the copyright holder. To view a copy of this licence, visit http://creativecommons.org/licenses/by$\mathrm{nc} / 4.0 /$.

\section{REFERENCES}

1. Kalra S, Arbinder S, Lathia T. What's in a name? Redefining type 2 diabetes remission. Diabetes Ther. 2021;24:1-8.

2. American Diabetes Association. 6. Glycemic targets: standards of medical care in diabetes-2019. Diabetes Care. 2019;42(Suppl 1):S61-70.

3. Gerstein HC, Miller ME, Byington RP, et al. Effects of intensive glucose lowering in type 2 diabetes. N Engl J Med. 2008;358(24):2545-59.

4. Davies MJ, D'alessio DA, Fradkin J, et al. Management of hyperglycemia in type 2 diabetes, 2018. A consensus report by the American Diabetes Association (ADA) and the European Association for the Study of Diabetes (EASD). Diabetes Care. 2018;41(12):2669-701.

5. Cornell S. Comparison of the diabetes guidelines from the ADA/EASD and the AACE/ACE. J Am Pharm Assoc (2003). 2017;57(2):261-5.

6. Buse JB, Caprio S, Cefalu WT, et al. How do we define cure of diabetes? Diabetes Care. 2009;32(11): 2133-5.

7. Fraser CG. Analytical goals for glucose analyses. Ann Clin Biochem. 1986;23(Pt 4):379-89.

8. Sjostrom L, Peltonen M, Jacobson P, et al. Association of bariatric surgery with long-term remission of type 2 diabetes and with microvascular and macrovascular complications. JAMA. 2014;311(22): 2297-304.

9. Nagi D, Hambling C, Taylor R. Remission of type 2 diabetes: a position statement from the Association of British Diabetologists (ABCD) and the Primary Care Diabetes Society (PCDS). Br J Diabetes. 2019;19:73-6. 
10. Pories WJ, Swanson MS, MacDonald KG, et al. Who would have thought it? an operation proves to be the most effective therapy for adult-onset diabetes mellitus. Ann Surg. 1995;222(3):339-50.

11. Buchwald H, Estok R, Fahrbach K, Banel D, Jensen Md, Pories WJ, et al. Weight and type 2 diabetes after bariatric surgery: systematic review and metaanalysis. Am J Med. 2009;122(3):248-56.

12. Taylor R, Al-Mrabeh A, Sattar N. Understanding the mechanisms of reversal of type 2 diabetes. Lancet Diabetes Endocrinol. 2019;7(9):726-36.

13. Prasad RB, Groop L. Precision medicine in type 2 diabetes. J Intern Med. 2019;285(1):40-8.

14. Bowman P, Flanagan SE, Hattersley AT. Future roadmaps for precision medicine applied to diabetes: rising to the challenge of heterogeneity. J Diabetes Res. 2018;2018:3061620.

15. Krentz NAJ, Gloyn AL. Insights into pancreatic islet cell dysfunction from type 2 diabetes mellitus genetics. Nat Rev Endocrinol. 2020;16(4):202-12.

16. Petersen MC, Schulman GI. Mechanisms of insulin action and insulin resistance. Physiol Rev. 2018;98(4):2133-223.

17. Wewer Albrechtsen NJ, Faerch K, Jensen TM, et al. Evidence of a liver-alpha cell axis in humans: hepatic insulin resistance attenuates relationship between fasting plasma glucagon and glucagonotropic amino acids. Diabetologia. 2018;61(3): 671-80.

18. Wewer Albrechtsen NJ, Pedersen J, Galsgaard KD, et al. The liver-alpha-cell axis and type 2 diabetes. Endocr Rev. 2019;40(5):1353-66.

19. Taylor R. Type 2 diabetes: etiology and reversibility. Diabetes Care. 2013;36(4):1047-55.

20. Carlsson LMS, Sjoholm K, Jacobson P, et al. Life expectancy after bariatric surgery in the swedish obese subjects study. N Engl J Med. 2020;383(16): 1535-43.

21. Svane MS, Toft-Nielsen MB, Kristiansen VB, et al. Nutrient re-routing and altered Gut-Islet Cell crosstalk may explain early relief of severe postprandial hypoglycaemia after reversal of Roux-En-Y gastric bypass. Diabet Med. 2017;34(12):1783-7.

22. Kushner RF, Calanna S, Davies M, et al. Semaglutide $2.4 \mathrm{Mg}$ for the treatment of obesity: key elements of the step trials 1 to 5 . Obesity (Silver Spring). 2020;28(6):1050-61.

23. Le Roux CW, Astrup A, Fujioka K, et al. 3 Years of liraglutide versus placebo for type 2 diabetes risk reduction and weight management in individuals with prediabetes: a randomised, double-blind trial. Lancet. 2017;389(10077):1399-409.

24. Henry RR, Scheaffer L, Olefsky JM. Glycemic effects of intensive caloric restriction and isocaloric refeeding in noninsulin-dependent diabetes mellitus. J Clin Endocrinol Metab. 1985;61(5):917-25.

25. Lim EL, Hollingsworth KG, Aribisala BS, Chen MJ, Mathers JC, Taylor R. Reversal of type 2 diabetes: normalisation of beta cell function in association with decreased pancreas and liver triacylglycerol. Diabetologia. 2011;54(10):2506-14.

26. Terranova CO, Brakenridge CL, Lawler SP, Eakin EG, Reeves MM. Effectiveness of lifestyle-based weight loss interventions for adults with type 2 diabetes: a systematic review and meta-analysis. Diabetes Obes Metab. 2015;17(4):371-8.

27. Butler AE, Janson J, Bonner-Weir S, Ritzel R, Rizza RA, Butler PC. Beta-cell deficit and increased betacell apoptosis in humans with type 2 diabetes. Diabetes. 2003;52(1):102-10.

28. Hojberg PV, Vilsboll T, Rabol R, et al. Four weeks of near-normalisation of blood glucose improves the insulin response to glucagon-like peptide- 1 and glucose-dependent insulinotropic polypeptide in patients with type 2 diabetes. Diabetologia. 2009;52(2):199-207.

29. Weng J, Li Y, Xu W, et al. Effect of intensive insulin therapy on beta-cell function and glycaemic control in patients with newly diagnosed type 2 diabetes: a multicentre randomised parallel-group trial. Lancet. 2008;371(9626):1753-60.

30. $\mathrm{Hu} \mathrm{Y,} \mathrm{Li} \mathrm{L,} \mathrm{Xu} \mathrm{Y,} \mathrm{et} \mathrm{al.} \mathrm{Short-term} \mathrm{intensive} \mathrm{therapy}$ in newly diagnosed type 2 diabetes partially restores both insulin sensitivity and beta-cell function in subjects with long-term remission. Diabetes Care. 2011;34(8):1848-53.

31. Chon S, Rhee SY, Ahn KJ, et al. Long-term effects on glycaemic control and beta-cell preservation of early intensive treatment in patients with newly diagnosed type 2 diabetes: a multicentre randomized trial. Diabetes Obes Metab. 2018;20(5): 1121-30.

32. Retnakaran R, Zinman B. Short-term intensified insulin treatment in type 2 diabetes: long-term effects on beta-cell function. Diabetes Obes Metab. 2012;14(Suppl 3):161-6.

33. Madsbad S, Dirksen C, Holst JJ. Mechanisms of changes in glucose metabolism and bodyweight after bariatric surgery. Lancet Diabetes Endocrinol. 2014;2(2):152-64. 